\title{
A política de cotas em um instituto superior de educação: as experiências de estudantes negros cotistas
}

\author{
Luiz Gustavo Borges do Rosario' \\ Josete Pereira Peres Soares ${ }^{2}$
}

\begin{abstract}
Resumo
Este artigo apresenta uma das ramificações das ações afirmativas, a política de cotas, investigando suas possibilidades. Objetivou-se investigar as possiveis interferências da utilização da política de cotas raciais e sociais. Para tanto, realizou-se uma coleta de dados por meio de questionários semiestruturados aplicados aos alunos negros cotistas do curso de pedagogia de um Instituto Superior de Educação, localizado no interior do Estado do Rio de Janeiro. Através dos relatos dos entrevistados, pôde-se constatar a importância das ações afirmativas não só como ferramenta de diversidade, mas também de garantia de justiça social.
\end{abstract}

\section{Palavras-chave}

Política de cotas; Justiça Social; Ensino superior público.

The quota policy in a higher education institute: the experiences of black quota students

\begin{abstract}
This article presents one of the ramifications of affirmative actions, the quota policy, investigating its possibilities. The objective was to investigate possible interference in the use of the racial and social quotas. To this end, a data collection was carried out through semi-structured questionnaires concerning black students from the pedagogy course of a Higher Education Institute, located in the interior of the State of Rio de Janeiro. Through the interviewees' reports, it was possible to verify the importance of affirmative actions not only as a tool of diversity, but also as a guarantee of social justice.
\end{abstract}

Keywords

Quota policy; Social Justice; Public higher education.

Artigo recebido: novembro de 2020

Artigo aprovado: dezembro de 2020 


\section{Introdução}

Carvalho (2011) constata que o Brasil é um país racista, em que a desigualdade social está intrinsecamente interligada à desigualdade racial. Ao considerar que essa realidade não pode ser normalizada dentro de uma sociedade, surgem as ações afirmativas, que buscam promover a igualdade de oportunidades e a redução das disparidades, caracterizando-se como um instrumento de transformação social.

A política de ações afırmativas, seja ela estabelecida por legislação ou criada por iniciativas das próprias instituições de ensino superior - especialmente os sistemas de reserva de vagas, popularmente denominada de cotas -, adquiriu notoriedade no Brasil a partir dos anos 2000. Essa política visa a assegurar um percentual de vagas para grupos específicos - em geral, os negros, os egressos de escolas públicas, que compõem em sua maioria a população carente e as pessoas com deficiência - e tem como objetivo a democratização do acesso ao ensino superior público e a redução das desigualdades sociais e étnico-raciais no país.

Hoje, mais de 15 anos depois das primeiras ações com as cotas, implementadas pela primeira vez no país pela Universidade do Estado do Rio de Janeiro (UERJ) e pela Universidade Estadual do Norte Fluminense Darcy Ribeiro (UENF), a partir da seleção de 2002/2003, essa política é obrigatória nas instituições públicas federais, mediante a promulgação da Lei n. ${ }^{\circ} 12.711$ (Brasil, 2012a), conhecida popularmente como Lei das Cotas, a qual prevê a reserva de $50 \%$ das vagas nas universidades e institutos federais para estudantes egressos de escolas públicas, em especial, negros e indígenas.

A partir desse cenário, neste artigo, buscou-se discorrer sobre a trajetória da população negra no ensino superior público brasileiro, abordando a problemática da desigualdade racial. Também se analisou a implementação das cotas no ensino superior por meio da Lei n. ${ }^{\circ}$ $12.711 / 12$. Especificamente, objetivou-se investigar as possiveis interferências da utilização da política de cotas raciais e sociais pelos alunos 
negros do curso de licenciatura em Pedagogia do Instituto Superior de Educação Professor Aldo Muylaert (ISEPAM), localizado em Campos dos Coytacazes/RJ, como ferramenta de inclusão social, bem como verificar a existência de conformidade entre as demandas dos universitários e as propostas dessa política.

Ao pesquisar as experiências desses alunos, diversos cenários foram apresentados. Os dados revelam que a política de cotas do ISEPAM apresenta diversas possibilidades para a efetivação da inclusão social desses alunos cotistas, todavia, alguns desafios, como a falta de tempo para estudar e o cansaço por terem uma rotina dupla, também foram introduzidos pelos entrevistados.

\section{Faces da desigualdade racial no Brasil}

Logo após a promulgação da Lei Áurea, ressalta-se que o Brasil não criou uma política de inclusão social entre os negros libertos com os demais membros da sociedade, o que ocasionou um problema histórico de desigualdade, que persiste até os dias atuais. Os negros não receberam nenhum tipo de oportunidade de educação, moradia ou trabalho. Para agravar a situação, durante os séculos XIX e XX, ocorreu um forte incentivo governamental de estímulo à imigração europeia. Com isso, os postos de trabalho deixados pelos negros foram ocupados por trabalhadores brancos e remunerados (RIBEIRO; PIOVESAN, 2008).

As desigualdades sociais - e principalmente as raciais - estão refletidas na educação, influenciando de forma negativa no acesso, na permanência e no sucesso dos grupos minoritários nos diferentes níveis e modalidades de ensino. Para Queiroz (1999):

Num país como o Brasil, apontado por exibir alarmantes estatísticas de repetência escolar, sobretudo nos anos iniciais da escolarização, é impossível falar em democratização das oportunidades educacionais sem tocar na questão das desigualdades raciais vigentes (QUEIROZ, 1999, p. 200). 
Como Araújo (2012) afırma, a escola, que se diz democrática, ainda continua perpetuando descriminação e excluindo de seu espaço aqueles a quem deveria acolher e formar. Segundo Cavalleiro (2001, p. 147), ao se acharem “[...] igualitárias, livre de preconceito e da discriminação, muitas escolas têm perpetuado desigualdades de tratamento e minado efetivas oportunidades igualitárias a todas as crianças".

Essa desigualdade racial no âmbito educacional é resultado de séculos de racismo, em que o negro não possuía o mínimo de dignidade ou direitos. Araújo (2014, p. 129) expõe que essas dificuldades educacionais que assolam a população negra contemporaneamente "[...] têm origem desde os tempos mais longínquos da história da educação brasileira e está estruturada sobre dois eixos: exclusão e abandono".

A intolerância para com as diferenças tem gerado conflitos e tensões. Vítimas frequentes de discriminação e preconceito, os grupos minoritários e historicamente discriminados são excluídos do mercado de trabalho, do sistema educacional, e dos meios tecnológicos, sendo-lhes negados direitos básicos (ARAÚJO, 2012). Como Paixão (2006, p. 18) pontua, “[...] o enfrentamento das questões derivadas das relações étnicas e raciais encontra-se, certamente, entre os maiores desafios da humanidade no século XXI".

A conjuntura da comunidade universitária contemporânea é um reflexo do longo caminho de desigualdade racial no Brasil. Carvalho e Segato (2002) mostram que, na virada do século XIX, ao invés de investir na qualificação dos ex-escravos, que agora tinham se tornado cidadãos do país, optou-se por substituir os poucos espaços conquistados pela população negra pelo estímulo e apoio à imigração europeia. Logo, em consequência dessa política racial deliberada de branqueamento, os europeus recém-chegados ao Brasil, que também possuíam baixa qualificação, em poucas décadas experimentaram uma ascensão social exorbitante, enquanto os negros foram "empurrados" sistematicamente para as margens da sociedade. 
Bertulio (2007) corrobora essa síntese expondo que o processo imigratório dos europeus, com comprometimento político e econômico do Estado, buscou reaparelhar a população brasileira em sua imagem branca e progressista, como merecia a nação brasileira, o maior país da América do Sul, contribuindo para manutenção da dicotomia das etnias branca e negra, com papéis superiores e inferiores na organização social.

Carvalho (2011) evidencia que, no início da década de 1930, quando foi criada a Faculdade Nacional de Filosofia - que mais tarde se tornaria a Universidade do Brasil -, a questão racial não foi discutida e se caracterizou pela ausência de questionamento, que estaria destinada a educar a mesma elite branca que predominava a época.

O mesmo aconteceu com a Universidade de São Paulo (USP), criada na mesma década. Como seus fundadores não avaliaram a questão da exclusão racial vigente no Brasil, a instituição também se viu destinada a expandir a elite intelectual branca do Brasil. Cabe ressaltar que a temática não foi discutida em ambas as universidades devido ao período histórico em que se encontrava o país. O debate acerca da inclusão/exclusão racial surgiu somente após a segunda metade do século XX. A escassez da população negra no ensino superior produzindo conhecimento e reflexão sobre a questão negra na educação deixou as instituições de ensino com pouca capacidade para refletir acerca de sua própria política racial e de autoavaliação a esse respeito.

Os negros sofreram uma dupla exclusão no ensino superior no começo do século XXI. A primeira, a exclusão do acesso, a segunda, a exclusão dos cursos de elite, como direito, medicina, odontologia, dentre outros. A população negra fica concentrada nos cursos chamados de baixa demanda, como licenciaturas, além disso, está concentrada também em instituições de menos prestígio.

Acerca dos anos 2000, é preciso enfatizar que a exclusão racial nas universidades ocorreu de norte a sul, de leste a oeste, aproximadamente na mesma intensidade. Das instituições de ensino superior, 
nenhuma é inteiramente integrada racial e etnicamente. É uma regra, sem exceção. A exclusão no meio acadêmico ainda tem sido estável e constante, o que a torna mais grave do que geralmente é relatado nas pesquisas e o que exige uma crítica mais profunda do grupo dominante - a população branca - que a reproduz há tanto tempo.

De acordo com Araújo (2014), a expansão do ensino público brasileiro se deu a partir dos meados do século XX, acarretada por meio do processo de industrialização e urbanização da sociedade, que gerou diversas mudanças. Uma dessas mudanças foi o início da prioridade do Estado por educação, que, até aquele momento, era privilégio de poucos. Esses poucos eram os grupos mais favorecidos, - a elite -, enquanto grande parte da população pobre - especificamente negros, que mais necessitava de instrução - era excluída do acesso ao sistema educacional.

Portanto, identificar os pontos de intervenção é somente constatar e concluir, mais uma vez, que a desigualdade é consequência da falta de intervenção que deveria ocorrer pelo mesmo grupo social ou racial predominante. Apesar de tantas preferências mecanizadas, a questão é que, até a atualidade, ninguém preferiu a população negra. Será necessário aprendermos a preferir essa população. Isto é, teremos que nos tornar ativamente e automaticamente antirracistas (CARVALHO, 2011).

Candau (2008) reconhece o Brasil como um país multicultural, e que possui em sua formação histórica a marca da eliminação física do “outro", por sua escravidão, ou negação do “outro", pela sua história trágica e dolorosa de conflitos e massacres. O multiculturalismo tem como premissa a promoção e o diálogo entre as várias culturas, como uma maneira de atuar, de intervir, de transformar a dinâmica social. Cabe ressaltar que a questão do multiculturalismo não nasceu nas universidades e no âmbito acadêmico em geral, mas nas lutas de grupos sociais discriminados e excluídos.

A formação de uma nova e genuína miscigenação é apontada como uma alternativa para engendrar novas ações de combate à segregação 
brasileira. Como Munanga (2014) defende, os aspectos definidores das políticas de ação afırmativa baseiam-se no reconhecimento das identidades no cenário nacional, que se caracteriza como uma questão de justiça social e direitos coletivos. Logo, a defesa da diversidade e do multiculturalismo é um fator primordial no processo de construção de uma cidadania duradoura e verdadeira.

As ações afırmativas são expostas como uma forma de inclusão racial, combate ao racismo e democratização do acesso da população negra no ensino superior brasileiro. Um dos pilares da concordância com a adoção da política de cotas seria o da reparação após mais de 300 anos de escravidão, uma vez que a população negra merece uma compensação por essa prática violenta e desumana. Outro motivo seria a cobrança de um direito, visto que a Constituição Federal de 1988 (BRASIL, 1988) assegura um tratamento igualitário a todos no que diz respeito aos serviços públicos oferecidos pelo Estado, incluindo o acesso ao ensino superior.

Um terceiro motivo seria a diversidade e pluralidade étnico-racial nas universidades. A presença dessa população minoritária enriquecerá a produção de saberes e irá forçar uma revisão do etnocentrismo $^{3}$, que marca a vida universitária brasileira. Acerca da problemática do etnocentrismo alocada junto à questão da meritocracia, Silva (2017) relata que

[...] a tese na qual a meritocracia se apoia é, em princípio, simples: todos os cidadãos são, a rigor, iguais perante a lei e, portanto, adotar ações afirmativas voltadas à comunidade afrodescendente sugere, implicitamente, que, além de se instituir uma distorção no plano dos direitos universais, considera essa mesma comunidade inatamente incapaz, necessitando de ajuda para se "desenvolver", perpetuando assim o preconceito (SILVA, 2017, p. 1210).

O autor ainda elucida que o ponto fraco da teoria da meritocracia encontra-se na ilusória premissa de que apesar de diferenças reais, isso não implica na concorrência igualitária. A política de cotas vem justa- 
mente desconjuntar e desconstruir esse fundamento bárbaro de exclusão, repondo os conceitos de meritocracia por outras normas e medidas de inclusão do corpo discente afrodescendente no meio acadêmico.

Sendo assim, a Lei n. ${ }^{\circ} 12.711$ (BRASIL, 2012a) não irá resolver defınitivamente a problemática da desigualdade racial nas universidades brasileiras. Trata-se apenas de um instrumento legítimo, entre vários utilizados ao redor do mundo, para compensar experiências históricas negativas de discriminação, injustiças, opressões e exclusão sofridas por grupos étnicos - ou até mesmo povos inteiros -, bem como democratizar o acesso desse grupo minoritário à educação superior, visando a minimizar a desigualdade racial.

Alberti e Pereira (2005) destacam como indutores das políticas afırmativas raciais, a relação entre a formação do movimento negro contemporâneo, a efervescência política no fım da ditadura, as agremiações de esquerda e a Igreja Católica, bem como a importância das manifestações artísticas e culturais.

\section{Trajetória das ações afirmativas no Brasil}

A discussão acerca de políticas para a igualdade racial ou de compensação para a população negra não é recente. Moehlecke (2004) revela que a primeira manifestação do que hoje conhecemos como ação afırmativa, ou cotas, surgiu em 1968, partindo da iniciativa de técnicos do Ministério do Trabalho e do Tribunal Superior do TrabaIho, que se manifestaram em prol da criação de uma Lei que assegurasse $20 \%$, $15 \%$ ou $10 \%$ para negros nas empresas em operação no Brasil, dependendo do ramo de atividade. No entanto, tal lei não chegou a ser elaborada.

Anos depois, na década de 1980, com a redemocratização do país, o deputado federal Abdias Nascimento elaborou e encaminhou ao Congresso Nacional o projeto de Lei $n .^{\circ}{ }^{1.332}$, de 1983, sendo o primeiro projeto de Lei propondo uma “ação compensatória" para a população negra em várias áreas sociais, buscando reparar os danos causados 
pelos séculos de discriminação sofrida (MOEHLECKE, 2004). Entretanto, como Baez (2017) revela, o projeto de Lei foi recusado:

A ideia era a de criar quotas no serviço público e incentivos às empresas do setor privado que contratassem afrodescendentes. Além disso, previa-se também a concessão de bolsas de estudos para essa população. Todavia, o Congresso Nacional rejeitou o projeto de lei, frustrando qualquer expectativa de início de políticas públicas voltadas à implementação de ações afırmativas no Brasil (BAEZ, 2017, p. 6).

Baez (2017) ainda ressalta que foi somente a partir da promulgação da Constituição Federal de 1988, que o Brasil reconheceu formalmente a existência da problemática da discriminação racial, de gênero e as diversas restrições enfrentadas pela população com deficiência e se propôs a enfrentá-los por meio da criação de ações afırmativas.

Moehlecke (2000) expõe que foi necessário aguardar mais alguns anos até que a temática étnico-racial entrasse na agenda política nacional, como ocorreu por meio do programa de combate ao racismo, apresentado pelo governo federal na Conferência Internacional contra o Racismo, Xenofobia e Intolerância, realizado em Durban, na África do Sul, em 2001. A partir disso, as políticas de ações afırmativas direcionadas à população negra ampliam-se no país.

Em 2002, ocorreu a criação do Programa Nacional de Ações Afirmativas, que estabeleceu políticas de discriminação positiva em favor de mulheres, negros e pessoas com deficiências, e que beneficiou fornecedores que desenvolveram políticas de inclusão social, com critérios de pontuação em licitações públicas, visando a incentivar ainda mais a inclusão desses grupos minoritários (BAEZ, 2017).

Segundo Machado (2013), o Estado do Rio de Janeiro foi pioneiro na reserva de vagas no ensino superior, através de uma legislação que entrou em vigor a partir da seleção de 2002/2003. Por meio de Lei estadual, foi determinada a reserva de vagas dos cursos de graduação das universidades estaduais para alunos oriundos de escolas públicas, 
selecionados por meio do Sistema de Acompanhamento do Desempenho dos Estudantes do Ensino Médio (SADE4).

Os programas de ações afırmativas que começaram a vigorar em algumas universidades do país surgiram interligadas à movimentos sociais que demandavam por maior igualdade e instrumentos que perpetuassem o acesso a bens e serviços para todos. Essas ações objetivaram uma desigualdade no tratamento como mecanismo de restituir uma igualdade, entre as etnias, que foi interrompida ou que nunca houve.

As ações afirmativas expandiram-se em vertentes distintas. A mais conhecida é o sistema de cotas, que se caracteriza na garantia de reserva de um determinado número ou percentual a ser ocupado em área específıca por grupo(s) definido(s). Assim,

Na definição dos grupos beneficiados, os projetos estabelecem critérios exclusivamente raciais/étnicos ou sociais, ou procuram utilizar ambos os critérios. Naqueles que estabelecem grupos raciais, temos como público-alvo os "negros", "afro-brasileiros", “descendentes de africanos", ou setores "etno-raciais socialmente discriminados”, em que estaria incluída a população indígena. Há projetos específıcos para a população denominada "carente" ou para os alunos oriundos da escola pública (MOEHLECKE, 2016, p. 426).

Moehlecke (2009, p. 481) ainda disserta a respeito do pouco conhecimento acerca dessa política, gerando uma confusão acerca dos desdobramentos das ações afırmativas. Frequentemente "[...] as ações afırmativas são associadas exclusivamente às políticas de cotas, sejam elas sociais, étnico/raciais, de gênero ou para deficientes", entretanto, existem outros casos em que essas ações afırmativas "[...] são definidas de modo a abranger qualquer política de inclusão social de caráter compensatório". Em suma:

A ação afırmativa pode ser uma preferência especial em relação a membros de um grupo definido por raça, cor, religião, língua ou sexo, com o propósito de assegurar acesso a poder, prestígio, riqueza [...] Essas definições introduzem a idéia da 
necessidade de promover a representação de grupos inferiorizados na sociedade e conferir-Ihes uma preferência a fim de assegurar seu acesso a determinados bens, econômicos ou não (MOEHLECKE, 2002, p. 200).

A pesquisadora também expõe uma concepção das ações afırmativas vista por uma perspectiva jurídica, afirmando que:

[...] ela surge como aprimoramento jurídico de uma sociedade cujas normas e mores pautam-se pelo princípio da igualdade de oportunidades na competição entre indivíduos livres, justificando-se a desigualdade de tratamento no acesso aos bens e aos meios apenas como forma de restituir tal igualdade [...] (MOEHLECKE, 2002, p. 200).

Como Baez (2017) defende, essas iniciativas desembocaram no impulsionamento do governo brasileiro a promulgar, em 2012, a Lei de Cotas. Apesar de todas as experiências com ações afırmativas no Brasil no começo da década, apenas quase 10 anos depois foi sancionada a primeira legislação federal garantindo a reserva de vagas.

Em 2012, quando a então Presidente da República, Dilma Rousseff, sanciona a Lei n. ${ }^{\circ} 12.711$ (Brasil, 2012a), 50\% das vagas passam a ser reservadas aos estudantes oriundos de famílias com renda igual ou inferior a um salário mínimo e meio per capita. Também serão reservadas vagas para autodeclarados pretos, pardos, indígenas e pessoas com deficiência (BRASIL, 2012a). A Lei Federal n. ${ }^{\circ} 12.711 / 12$ apresenta-se em um momento de relativa consolidação das políticas de ações afırmativas para democratização do acesso às instituições de ensino superior públicas do Brasil (GUERRINI et al., 2018).

Em um levantamento de dados realizado pelo Grupo de Estudos Multidisciplinares da Ação Afırmativa (GEMAA), em 2011, um ano antes da aprovação da Lei n. ${ }^{\circ} 12.711,70$ das 98 universidades públicas federais e estaduais adotavam a política de cotas em seus respectivos processos de seleção de estudantes para ingressos nos cursos de graduação (FERES JÚNIOR; DAFLON; CAMPOS, 2011). 
A Lei é regulamentada pelo Decreto n. ${ }^{\circ}$ 7.824, de 11 de outubro de 2012 (Brasil, 2012b), e pela Portaria Normativa n. ${ }^{\circ}$ 18, de 11 de outubro de 2012 (Brasil, 2012c), que disserta sobre a implementação das reservas de vagas em instituições de ensino. Esses são os Documentos que respaldam a atual política de cotas no ensino superior (LADEIRA; SILVA, 2018).

Como Guerrini et al. (2018) explicam, algumas instituições que já possuíam algum tipo de política de reserva de vagas tiveram que começar a se adequar à nova legislação, o que ocasionou mudanças já nos processos seletivos de 2013. Santos (2013) afirma que a Lei proporcionou um aumento significativo de vagas para alunos oriundos de escolas públicas e não brancos e, consequentemente, um aumento significativo de negros de escolas públicas nas universidades federais. Afırmação essa que desmistifica o mito da ineficácia da política de cotas e é corroborado por dados da mais recente pesquisa das “Desigualdades Sociais por Cor ou Raça no Brasil”, realizada pelo IBCE (2019), baseado no Pnad Contínua, que revela que o número de estudantes negros nas universidades públicas passou, pela primeira vez, o de estudantes brancos, sendo 1.014.000 negros matriculados no ensino superior público contra 1.005.000 brancos matriculados.

Apesar dos números históricos do Pnad Contínua (IBCE, 2019) e o fato de representarem agora mais da metade dos estudantes do ensino superior público, a população negra permanece sub-representada, já que são 55,8\% da população brasileira. Em 2018, apenas 35,4\% dos negros com ensino médio completo chegavam ao ensino superior (público ou privado). Entre a população branca, esse número era de 53,2\%.

Considerando toda a trajetória de desigualdade sofrida pelos negros desde os tempos da escravidão, esses são números animadores, entretanto, como mencionado, ainda não é o número ideal, visto que essa população é maioria no Brasil, logo, não podem ser sub-representados na sociedade, seja no mercado de trabalho ou na educação, porém, com o auxílio das cotas, essa desigualdade vem sendo nivelada. 


\section{Análise e discussão dos dados}

A seleção dos alunos entrevistados ocorreu por meio de um questionário online no Google Forms, com perguntas semiestruturadas, que abordaram questões como: ano de ingresso na graduação; escolaridade dos pais; perspectivas acerca da trajetória discente enquanto cotista.

Após elaboração das perguntas, o link do questionário foi enviado para os representantes de suas respectivas turmas a fim de ser divulgado para os demais alunos e, assim, ser respondido. O questionário foi enviado para sete turmas do curso de pedagogia, do $1^{\circ}$ ao último ${ }^{5}$ período do curso.

Após o envio do link do questionário, houve uma espera de uma semana para que os alunos dos sete períodos contatados pudessem responder. Ao final do prazo estipulado, apenas 14 alunos se disponibilizaram a responder ao questionário, um número inexpressível, considerando a quantidade de alunos que receberam o link. Os alunos que responderam tornaram-se os sujeitos-objeto desta pesquisa.

O método usado para a análise dos dados foi a técnica de triangulação. Nessa técnica, todos os dados coletados são devidamente organizados, interligados e interpretados pelo pesquisador, tendo embasamento nos fundamentos teóricos. Para Triviños (1999), essa técnica permite um meIhor aprofundamento da descrição, explicação e compreensão do objeto em estudo, uma vez que um fenômeno social não pode ser interpretado de forma isolada, sem considerar as raízes históricas, os significados culturais e as vinculações tênues e necessárias com sua realidade social.

Foram investigadas junto aos 14 discentes entrevistados, múltiplas questões, as quais perpassaram por aspectos relacionados à instituição, ao curso e ao próprio discente. Os entrevistados não tiveram os seus nomes divulgados, sendo denominados como D1, D2, D3, D4, D5, D6, D7, D8, D9, D10, D11, D12, D13 e D14.

No Quadro 1 são apresentados os perfis dos estudantes entrevistados, contendo dados no que tange ao período em que o aluno se encontra, sua idade, sua etnia e o ano de ingresso no curso de licenciatura em pedagogia do ISEPAM. 


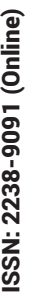

Quadro 1: Perfis dos alunos entrevistados

\begin{tabular}{|l|l|l|l|l|}
\hline Discentes & Período & Idade & $\begin{array}{l}\text { Etnia (de acordo com o } \\
\text { IBGE) }\end{array}$ & $\begin{array}{l}\text { Ano de } \\
\text { ingresso no } \\
\text { curso }\end{array}$ \\
\hline D1 & $3^{\circ}$ & 20 & Parda & 2018 \\
\hline D2 & $2^{\circ}$ & 31 & Preta & 2019 \\
\hline D3 & $7^{\circ}$ & 23 & Preta & 2016 \\
\hline D4 & $3^{\circ}$ & 51 & Parda & 2018 \\
\hline D5 & $2^{\circ}$ & 25 & Preta & 2019 \\
\hline D6 & $2^{\circ}$ & 25 & Parda & 2019 \\
\hline D7 & $2^{\circ}$ & 20 & Parda & 2019 \\
\hline D8 & $6^{\circ}$ & 24 & Negra & 2017 \\
\hline D9 & $4^{\circ}$ & 20 & Preta & 2018 \\
\hline D10 & $6^{\circ}$ & 20 & Preta & 2017 \\
\hline D11 & $7^{\circ}$ & 31 & Parda & 2016 \\
\hline D12 & $7^{\circ}$ & 21 & Preta & 2016 \\
\hline D13 & $1^{\circ}$ & 20 & Parda & 2019 \\
\hline D14 & $6^{\circ}$ & 20 & Preta & 2017 \\
\hline
\end{tabular}

Fonte: elaboração dos autores

Os Gráficos 1 e 2 trazem dados coletados relativos à escolaridade dos pais dos alunos entrevistados:

Gráfico 1: Escolaridade das mães dos discentes entrevistados

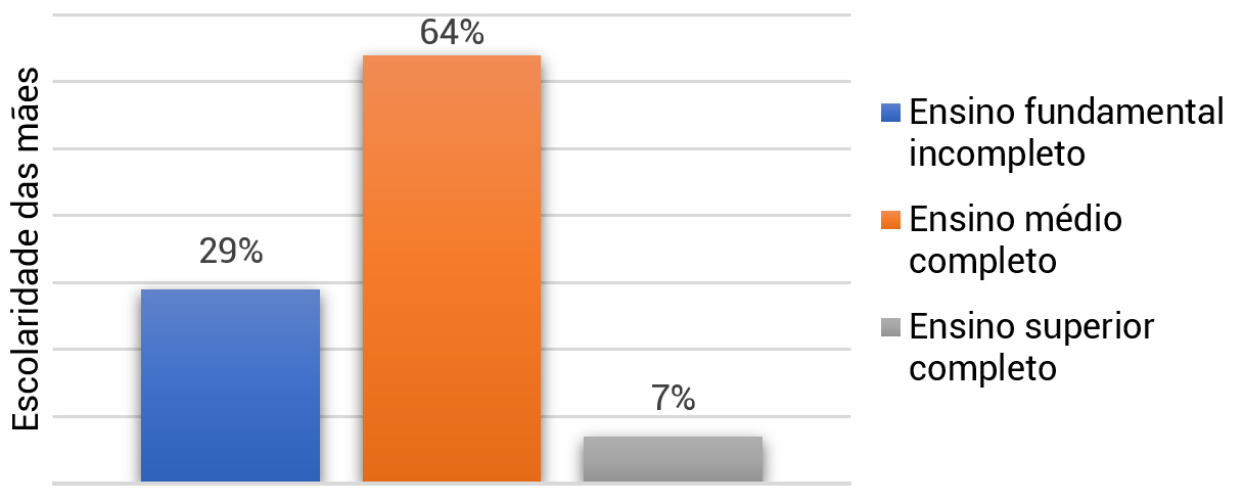

Fonte: elaboração dos autores. 
Segundo o PNAD Contínua (IBGE, 2019), a média de anos de estudo das pessoas de 25 anos ou mais de idade, em 2018, foi 9,3 anos. Desde 2016, essa média vem crescendo gradativamente anualmente 0,2 ano. Entre as mulheres, o número médio de anos de estudo foi de 9,5 anos. Considerando os dados do Gráfico 1, 71\% das mães dos entrevistados estão acima da taxa de escolaridade média nacional e da taxa de escolaridade média de estudo pertencente as mulheres brasileiras. Entretanto, 29\% das mães dos entrevistados possuem o ensino fundamental incompleto, ou seja, estão abaixo da taxa de escolaridade média nacional e da taxa de escolaridade média de estudo pertencente às mulheres brasileiras.

Gráfico 2: Escolaridade dos pais dos discentes entrevistados

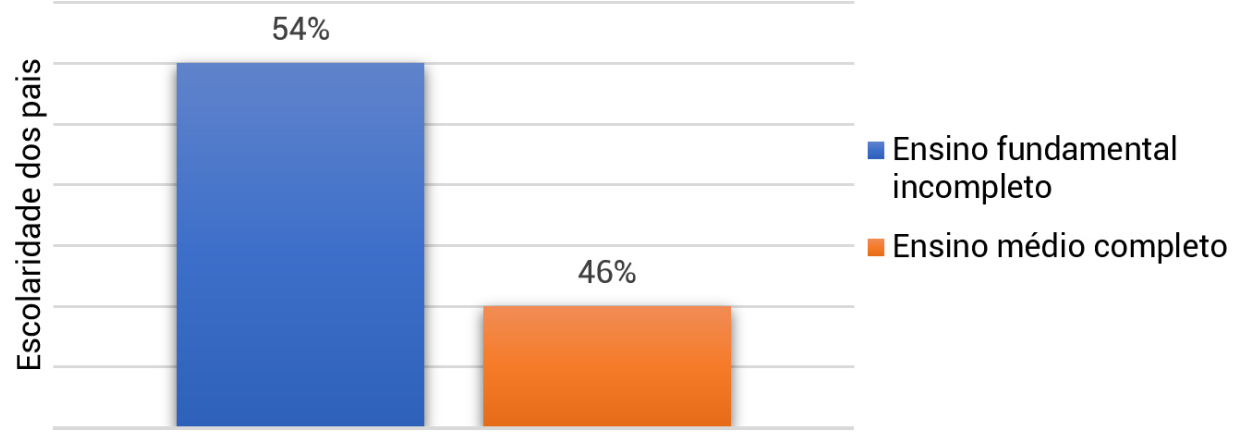

Fonte: elaboração dos autores.

Para os homens, ainda em consonância com o PNAD Contínua (IBGE, 2019), a taxa média de anos de estudos caracteriza-se como 9 anos. Considerando que no Gráfico 2 os alunos entrevistados revelaram que $46 \%$ dos seus pais possuem ensino médio completo, essa porcentagem está acima da taxa de escolaridade média nacional e da taxa de escolaridade média de estudo pertencente aos homens brasileiros. No entanto, nesse gráfico também é revelado que 54\% dos pais dos entrevistados possuem ensino fundamental incompleto, isto é, estão abaixo da taxa de escolaridade média nacional e da taxa de escolaridade média de estudo pertencente aos homens brasileiros. 
A gravidade dos dados é ampliada ainda mais quando, dos 14 entrevistados, 13 revelam ser os primeiros membros de suas respectivas famílias a ingressarem no ensino superior. Tal número mostra a vigente desigualdade educacional no Brasil e, como Moehlecke (2002) expõe, o insignificante acesso da população pobre e negra ao ensino superior brasileiro, além da incompatibilidade dessa situação com a ideia de igualdade, justiça e democracia.

Outra pergunta realizada aos entrevistados diz respeito às maiores dificuldades para permanecer no curso. Essa pergunta foi apresentada na forma de múltipla escolha. Obtiveram-se as seguintes respostas como as mais comuns: materiais (xerox e outros), transporte, tempo para estudar e cansaço (Gráfico 3).

Gráfico 3: Posicionamento dos alunos sobre as dificuldades para continuar no curso



\section{Fonte: elaboração dos autores.}

Pode-se observar, ao longo dos depoimentos, que a questão do acesso encontra-se em desenvolvimento satisfatório, o que representa, na opinião dos alunos entrevistados, a eficácia das cotas. Entretanto, no que tange à permanência, como é possível analisar no Gráfico 3 , diversos são os desafios para dar continuação ao curso e, consequentemente, à conclusão da graduação. 
Moehlecke (2004) destaca que deve ocorrer uma redefinição nos mecanismos de permanência do aluno cotista, visando a garantir oportunidades mais inclusivas e equitativas. É necessário haver iniciativas relacionadas à trajetória do aluno no curso, incorporando políticas que não abranjam somente o acesso, mas, também, à permanência. Para isso, é preciso haver uma ação coletiva, visando a estratégias que culminem na permanência dos alunos cotistas no ISEPAM. Uma dessas ações constitui-se da bolsa auxílio, conferida aos alunos que optam por ingressar pelo sistema de cotas em sua entrada na instituição, prosseguindo até a conclusão da graduação.

Outra pergunta feita aos entrevistados consistiu em saber o que ingressar no curso agregou na vida deles. Para isso, foram apresentadas múltiplas opções a serem escolhidas. No Gráfico 4 é possível observar as respostas mais frequentes dos estudantes.

Gráfico 4: Posicionamento dos alunos sobre as oportunidades a partir do ingresso no curso

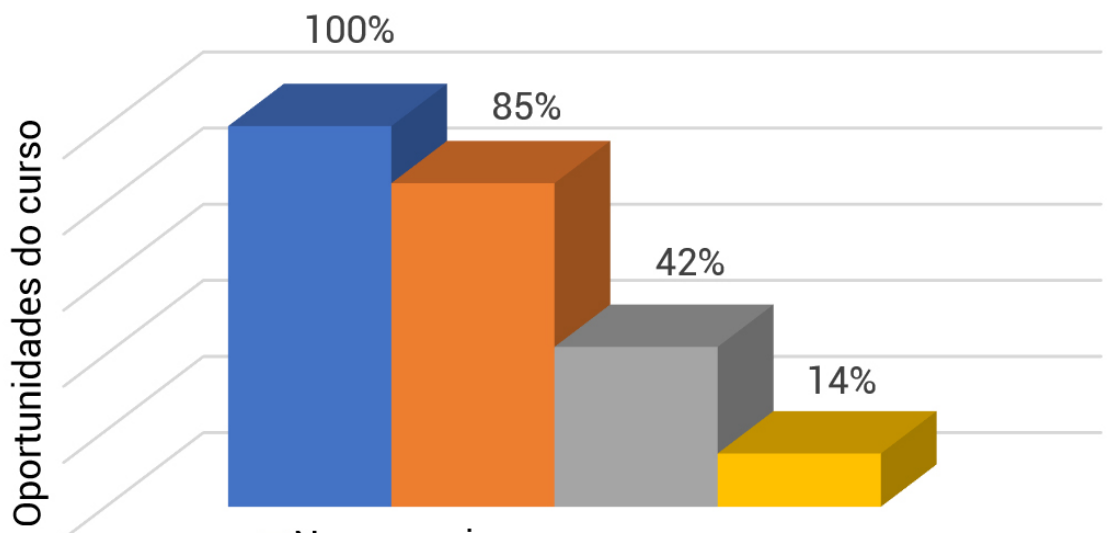

Novos amigos

Novo repertório de conhecimentos

Oportunidade de emprego

Nova visāo social

Fonte: elaboração dos autores. 
Como é possivel analisar no Gráfico 4, as respostas mais comuns obtidas foram: oportunidade no mercado de trabalho, novo ciclo de amizades e um novo repertório de conhecimentos. A partir das respostas dos entrevistados nota-se o que Moehlecke (2004) ressalta ao elencar que as ações afırmativas estão intrinsecamente interligadas a sociedades democráticas, tendo como pauta igualdade de oportunidades como seus principais valores. Essas ações propõem uma desigualdade de tratamento para restituir uma igualdade rompida ou que nunca existiu, trazendo consigo a efetivação da justiça social.

Como Rawls (1997) relata, a justiça distributiva só pode ser alcançada quando forem satisfeitos os dois principais princípios de justiça, sendo eles: o da liberdade igual e o da igualdade equitativa de oportunidades. Partindo dessa concepção, a política de cotas nas universidades aparece como uma alternativa de reverter o quadro de injustiça que acompanha a história da sociedade brasileira, em que ocorre a exclusão de uma grande parcela da sociedade em busca de condições para elevar seu patamar social, cultural e econômico.

Sendo as instituições de ensino, especialmente as públicas, alicerces da estrutura básica da sociedade, elas deveriam ser, sob a ótica dos princípios da justiça com equidade, distribuidoras de oportunidades para os grupos menos favorecidos e excluídos, e não participantes de uma elite que pouco coopera para a distribuição das vantagens provenientes da cooperação social.

Pode-se considerar a política de cotas como agente transformador da sociedade, bem como um instrumento de inclusão social, uma vez que oportuna a esses alunos excluídos socialmente durante o ensino médio, o acesso ao que podemos chamar de um "novo mundo" de oportunidades: o ensino superior.

Como relatado, após o ingresso no ensino superior público por meio das ações afirmativas, os estudantes entrevistados entraram em contato com oportunidades antes negada a eles, seja por questão de classe ou etnia. Conforme ressaltado por Moehlecke (2002), 
foi encontrada, nesta pesquisa, referência à importância atribuída à educação, vista como uma ferramenta de ascensão social e de desenvolvimento do país.

Mediante os depoimentos dos discentes entrevistados do ISEPAM, o sistema de cotas na instituição ainda necessita de aperfeiçoamentos, no entanto, segundo a apreciação dos depoimentos dos discentes entrevistados, é possível notar inferência de caráter geral, como o quanto essa política teve impacto positivo na vida pessoal e acadêmica dos alunos. Por meio da aplicação dessa política, foi possível resgatar uma dívida social e histórica, e assim, ampliar oportunidades para quem não teve, como foi o caso dos alunos entrevistados.

\section{Considerações finais}

A política de ações afırmativas emerge como um instrumento para a redução dos abismos sociais entre os diferentes grupos étnicos, buscando, desse modo, proporcionar um ambiente de interação social. Entretanto, o sistema de cotas isoladamente não garante uma solução para o cumprimento do direito à educação - nesse caso, de nível superior -, mas caracteriza-se como uma importante ferramenta de combate à desigualdade entre negros e brancos.

Os parâmetros norteadores das ações afırmativas são guiados pela certifıcação das identidades em solo nacional, o que se define como um caso de justiça distributiva e direitos coletivos. Portanto, a defesa da diversidade cultural em sociedade é um coeficiente fundamental no processo de construção de uma cidadania efetiva.

Refletindo acerca dessas questões, o interesse da presente pesquisa foi averiguar de que forma a política de cotas vem sendo analisada e avaliada pelo seu público-alvo: estudantes cotistas. Para tanto, contemplou como objetivo geral descobrir se a política de cotas caracterizava-se como um possível instrumento de inclusão social. Na busca para alcançar esse objetivo, mapeou-se o curso de pedagogia do ISEPAM, partindo das narrativas dos alunos cotistas. 
Verificou-se, durante a pesquisa com os estudantes entrevistados, que a maioria caracterizava-se em situação econômica de baixa renda, evidenciando, desse modo, como a política de cotas desenvolveu um papel fundamental no ingresso desses alunos no ensino superior público, visto que eles não possuem renda necessária para ingressar em cursos no ensino superior privado.

Outro fator de evidência notado foi que, dos 14 alunos entrevistados, 13 possuem pais com escolaridade máxima até o ensino médio apenas, e somente 1 (um) possui mãe com formação superior, no entanto, o pai possui apenas o ensino fundamental.

A partir dos depoimentos e dos dados coletados, foi possível mensurar o impacto da política de cotas na vida dos alunos do ISEPAM. A maioria deles revelou ser o primeiro da família a ingressar no ensino superior, bem como a ter acesso e ser introduzido a uma nova gama de conhecimentos e experiências oferecidas pela sociedade contemporânea por meio desse acesso ao ensino superior.

A análise da importância das cotas para a inclusão social e acesso ao ensino superior por meio das experiências dos estudantes negros que utilizaram o sistema de cotas do ISEPAM permitiu a compreensão da importância das ações afirmativas não só como ferramenta de diversidade, mas também de garantia de justiça social. Através dos relatos dos entrevistados, o ensino superior é visto como um caminho para a ascensão da condição social. Nesse sentido, programas e políticas educacionais poderão servir como impulsores de políticas de inclusão social, portanto, de redução das desigualdades sociais e raciais.

\section{Referências}

ALBERTI, Verena; PEREIRA, Amilcar Araujo. As Articulações entre movimento negro e Estado: estratégias e experiências contemporâneas. In: GOMES, Angela C. (Org). Direitos e cidadania: memória, política e cultura. Rio de Janeiro: FGV, 2007, p. 93-113. 
ARAÚJO, Jurandir de Almeida. Educação, desigualdade e diversidade: grupos menos favorecidos frente ao sistema escolar brasileiro. Revista da Associação Brasileira de Pesquisadores/as Negros/as (ABPN), v. 4, n. 8, p. 114-125, 2012.

ARAÚJO, Jurandir de Almeida. Educação e desigualdade: a conjuntura atual do ensino público no Brasil. Revista Direitos Humanos e Democracia, v. 2, n. 3, p. 125-157, 2014.

BAEZ, Narciso Leandro Xavier. A construção histórica das ações afirmativas para afrodescendentes no Brasil. Revista Brasileira de Direito, v. 13, n. 3, p. 1-13, 2017.

BERTULIO, Dora Lucia de Lima. Ação Afırmativa no Ensino Superior: considerações sobre a responsabilidade do Estado Brasileiro na promoção do acesso de negros à Universidade - o Sistema Jurídico Nacional. In: PACHECO, Jairo Queiroz; SILVA, Maria Nilza da (Orgs.). O negro na universidade: o direito a inclusão. Brasília, DF: Fundação Cultural Palmares, 2007.160 p.

BRASIL. Constituição da República Federativa do Brasil. Brasília, DF: Senado Federal: Centro Gráfico, 1988.

BRASIL. Lei $n^{\circ} 12.711$, de 29 de agosto de 2012. Dispõe sobre o ingresso nas universidades federais e nas instituições federais de ensino técnico de nível médio e dá outras providências. Seção 1, p. 1. Diário Oficial da União, Brasília, 30 ago. 2012a.

BRASIL. Decreto $n .{ }^{\circ} 7.824$, de 11 de outubro de 2012. Regulamenta a Lei no 12.711, de 29 de agosto de 2012, que dispõe sobre o ingresso nas universidades federais e nas instituições federais de ensino técnico de nível médio. Diário Oficial da União, Brasília, DF, 15 out 2012b.

BRASIL. Portaria Normativa n. ${ }^{\circ} 18$, de 11 de outubro de 2012. Diário Oficial da União. Imprensa Nacional. Brasília, DF: 15 out. 2012c, n. ${ }^{\circ}$ 199, seção 1, p. $16-$ 18. Disponivel em: https://pesquisa.in.gov.br/imprensa/jsp/visualiza/index. jsp?jornal=1\&pagina=16\&data=15/10/2012. Acesso em: 23 out. 2020.

CANDAU, Vera. Multiculturalismo e educação: desafios para a prática pedagógica. In: MOREIRA, Antônio Flávio Barbosa; CANDAU, Vera (Orgs.). Multiculturalismo: diferenças culturais e práticas pedagógicas. 2. ed. Petrópolis: Vozes, 2008.

CARVALHO, José Carlos de Paula. Etnocentrismo: inconsciente, imaginário e preconceito no universo das organizações educativas. Interface - Comunicação, Saúde, Educação, v. 1, n. 1, p. 181-186, 1997. 
CARVALHO, José Jorge de; SECATO, Rita Laura. Uma Proposta de Cotas para Estudantes Negros na Universidade de Brasília. Brasília, 2002. Série Antropologia. Disponível em: http://www.dan.unb.br/images/doc/Serie314empdf. pdf. Acesso em: 12 out. 2020.

CARVALHO, José Jorge de. Inclusão Étnica e Racial no Ensino Superior: Um Desafio para as Universidades Brasileiras. In: NUNES, Margarete Fagundes (Org.). Diversidade e Políticas Afirmativas: Diálogos e Intercursos. Novo Hamburgo: FEEVALE, 2005.

CARVALHO, José Jorge de. Inclusão Étnica e Racial no Brasil: a questão das cotas no ensino superior. 2. ed. São Paulo: Attar Editorial, 2011.

CAVALLEIRO, Eliane. Educação anti-racista: compromisso indispensável para um mundo melhor. In: CAVALLEIRO, Eliane (Org.). Racismo e anti-racismo na educação: repensando nossa escola. São Paulo: Selo Negro, 2001, p. 141-160.

FERES JÚNIOR, João; DAFLON, Verônica Toste; CAMPOS, Luiz Augusto. A ação afirmativa no ensino superior brasileiro. Rio de Janeiro: UERJ/IESP, 2011. (Levantamento das Políticas de Ação Afırmativa - CEMAA).

GUERRINI, Daniel et al. Acesso e democratização do ensino superior com a Lei $n^{\circ}$ 12.711/2012: o câmpus de Londrina da Universidade Tecnológica Federal do Paraná (UTFPR). Revista Brasileira de Estudos Pedagógicos, v. 99, n. 251, p. 17-36, 2018.

IBCE - Instituto Brasileiro de Geografia e Estatística. Ministério da Economia. Desigualdades Sociais por Cor ou Raça no Brasil. Rio de Janeiro: Pesquisa Nacional por Amostra de Domicílios (PNAD), 2019. Disponível em: https://biblioteca.ibge.gov.br/visualizacao/livros/liv101681_notas_tecnicas.pdf. Acesso em: 23 out 2020 .

LADEIRA, Mariana Rosa Alves; SILVA, Hilda Maria Gonçalves da. (Des)caminhos do sistema brasileiro de cotas universitárias. Temporalis, v. 18, n. 35, p. 220-243, jan./jun. 2018.

MACHADO, Elielma Ayres. Ação Afirmativa, Reserva de Vagas e Cotas na Universidade do Estado do Rio de Janeiro (2002-2012). Coleção Estudos Afirmativos. Rio de Janeiro: Flacso, GEA; UERJ; LPP, 2013.

MOEHLECKE, Sabrina. Propostas de ações afirmativas no Brasil: o acesso da população negra ao ensino superior. 2000. 179 f. Dissertação (Mestrado em Educação) - Faculdade de Educação. Universidade de São Paulo, São Paulo. 
MOEHLECKE, Sabrina. Ação afırmativa: História e debates no Brasil. Caderno de Pesquisa, n. 117, p. 197-217, 2002.

MOEHLECKE, Sabrina. Ação afırmativa no ensino superior: entre a excelência e a justiça racial. Educação \& Sociedade, v. 25, n. 88, p. 757-776, 2004.

MOEHLECKE, Sabrina. As políticas de diversidade na educação no governo Lula. Caderno de Pesquisa, v. 39, n. 137, p. 461-487, 2009.

MOEHLECKE, Sabrina. Ação afırmativa no Brasil: um histórico do seu processo de construção. In: FONSECA, Marcus Vinicius; BARROS, Surya Aaronovich Pombo. (Orgs.). A história da educação dos negros no Brasil. Niterói: UFF, 2016, p. 1-442.

MUNANGA, Kabengele. A questão da diversidade e da política de reconhecimento das diferenças. Crítica e Sociedade, v. 4, n. 1, p. 34-45, 2014.

PAIXÃO, Marcelo. Manifesto Anti-Racista: Ideias em prol de uma utopia chamada Brasil. Rio de Janeiro: DP\&A; LPP/UERJ, 2006.

QUEIROZ, Delcele Mascarenhas. "Raça" e educação na Bahia nos anos 90. Revista da FAEEBA - Educação e Contemporaneidade, n. 12, p. 199-221, jul./ dez. 1999.

RAWLS, John. Uma Teoria da Justiça. 4. ed. São Paulo: Martins Fontes, 1997.

RIBEIRO, Matilde; PIOVESAN, Flávia. Dossiê 120 anos de abolição. Revista de Estudos Feministas, v. 16, n. 3, p. 879-885, dez. 2008.

SANTOS, Jocélio Teles dos (Org.). O impacto das cotas nas universidades brasileiras (2004-2012). Salvador: Centro de Estudos Afro-orientais, 2013.

SILVA, Maurício. Cotas raciais na universidade brasileira e a ideologia da meritocracia. Revista Diálogo Educação, v. 17, n. 54, p. 1207-1221, jul./set. 2017.

TRIVIÑOS, Augusto Nibaldo Silva. Introdução à pesquisa em ciências sociais: A pesquisa qualitativa em educação. São Paulo: Atlas, 1999.

\section{Notas}

1 Licenciado em Pedagogia pelo Instituto Superior de Educação Professor Aldo Muylaert, Campos dos Coytacazes/RJ, Brasil. ORCID: orcid.org/0000-00021827-8209. E-mail: luizgustavoborges@outlook.com.br

2 Doutora em Políticas Sociais pela Universidade Estadual do Norte Fluminense Darcy Ribeiro, Campos dos Goytacazes/RJ, Brasil. Professora do curso de Licenciatura em Pedagogia do Instituto Superior de Educação Professor Aldo Muylaert. ORCID: orcid.org/0000-0001-7574-4993. E-mail: joseteppsoares@yahoo.com.br 
3 O etnocentrismo consiste em privilegiar um universo de representações, propondo-o como modelo e reduzindo à insignificância os demais universos e culturas "diferentes" (CARVALHO, 1997).

4 O SADE tem como objetivo avaliar o desempenho dos estudantes do ensino médio mantidos pelo Poder Público, com a finalidade de preenchimento de 50\% das vagas dos cursos de graduação da Universidade do Estado do Rio de Janeiro (UERJ) e da Universidade Estadual do Norte Fluminense (UENF), levando-se em consideração cursos/habilitações, semestres e turnos, obedecida a limitação de vagas existentes, a serem preenchidas de acordo com o critério da melhor nota.

5 Até o semestre de 2018.2, a matriz curricular do curso contava apenas com 7 períodos. A partir de 2019.1, a matriz curricular foi reorganizada e passou a contar com 8 períodos. 